\title{
Immature Lymphocytes Measurement
}

National Cancer Institute

\section{Source}

National Cancer Institute. Immature Lymphocytes Measurement. NCI Thesaurus. Code C100444.

The determination of the amount of immature lymphocytes present in a sample. 